\title{
Der Nabel der Welt
}

\section{Erhard Taverna}

Dr. med., Mitglied der Redaktion

Vom Kreis der Narwalzähne, den Daniel Spörri als Nabel der Welt bezeichnet, reicht der Blick weit über Seggiano und die dicht bewaldeten Hügel der südlichen Toskana. Hier, am Abhang des Monte Amiata, fand der Künstler das Land für seinen Park der Skulpturen. Durch das ausgedehnte Areal führen Fusswege durch die ungemähten Wiesen, wo roter Klee und gelber Hahnenfuss blühen. Seit 1991 sind immer wieder neue Kunstwerke befreundeter Künstler zu Spörris eigenen

Durch das ausgedehnte Areal führen Fusswege durch die ungemähten Wiesen, wo roter Klee und gelber Hahnenfuss blühen.

Werken dazu gekommen. Zur vorläufig letzten Einweihung einer Skulptur von Maineri 2016 ist auch der 87-jährige Meister aus Wien angereist.

Die schmalen Naturwege mäandern auf und ab durch etwa sechs gleich grosse, durch Hecken und kleine
Wälder unterteilte Bezirke, mehr Park, als der Name «Giardino» vermuten lässt. Auf den kargen Ton- und Kalkböden wachsen Olivenbäume, vereinzelt wilde Kastanien und Reste ehemaliger Rebstöcke. Es riecht nach Minze und Macchia, Tauben gurren, Schwalben durchpfeilen den klaren Himmel. Immer wieder führen kleine Tuffsteintreppen zu verborgenen Schätzen, $\mathrm{zu}$ einem riesigen $\mathrm{Ei}$, einem kleinen Werwolf, einer Gruppe von Frauen auf einem Podest mit einem wunderbaren Weitblick. Überraschende Funde aus Stahl, Bronze, Granit oder Beton im Freien oder im Schatten der Wacholder, Ginster, Stechpalmen oder Holunderbüsche. Ein Speierling da, ein Feigenbaum dort, wer will kann die 16 Hektaren Land auch als beschilderten Botanik-Lehrpfad ablaufen. An die 55 Künstler haben zu diesem Universum beigetragen, darunter sind viele vertraute Namen wie Eva Aeppli, Meret Oppenheim, Bernhard Luginbühl, Jean Tinguely und Katharina Duwen, die das Werk ihres Ehemannes als Poesiealbum

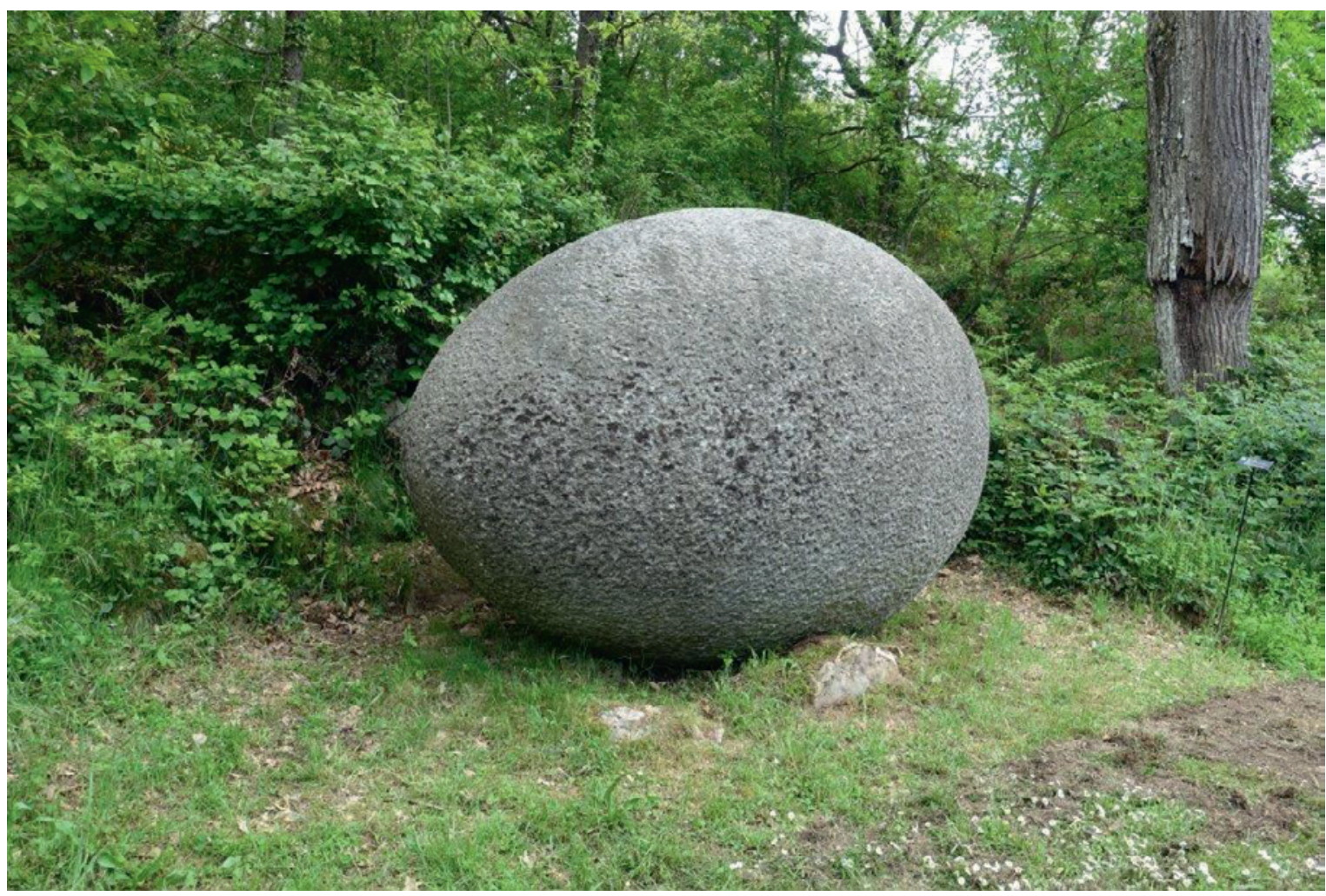

Herbert Distel, Denkmal. 


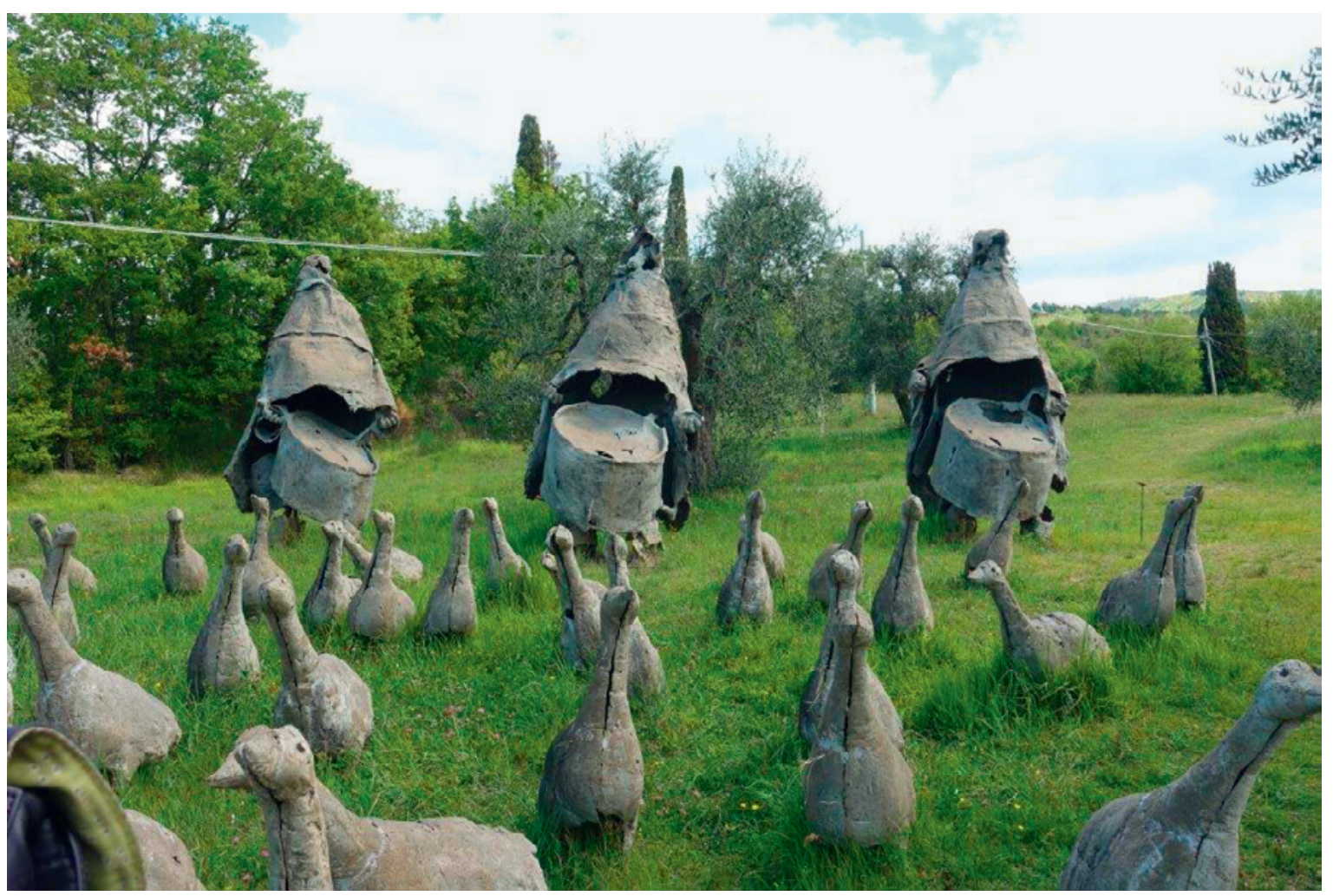

Olivier Estoppey, Tag des Zorns.

bezeichnete. Die Skulpturen sind witzig, verspielt, bedrohlich, grotesk, surreal und ironisch. Daniel Spörri hat ein Gesamtkunstwerk geschaffen, das den Betrachter mit Liebe und Tod, Sex, Einsamkeit und Kampf konfrontiert. Auch mit der Übermacht einer Natur, die

Die Skulpturen sind witzig, verspielt, bedrohlich, grotesk, surreal und ironisch.

Menschenwerke nur auf Zeit duldet, bevor sie Efeu darüber wachsen oder diese zu Rost zerfallen lässt. Ein Vorbild für seine Vision fand er im Garten von Bomarzo aus der späten Renaissance, der nach Jahrhunderten ein zweites Mal der Natur entrissen wurde. Daniel Spörri, geboren 1930 in Rumänien, ist ein Multitalent. Nachdem sein Vater von den Nazis verschleppt und ermordet wurde, flüchtete seine Mutter, eine Schweizerin, mit ihm nach Zürich. Zum Tänzer ausgebildet war er am Berner Stadttheater, fand in Paris zur Bühne, war Regieassistent in Darmstadt, publizierte eine Poesie-Zeitschrift, schuf mobile Kunst, erfand Kochbücher, restaurierte eine Mühle in Frankreich, bewies sich als Schöpfer zahlreicher Bronze-Kunstwerke und amtete als Professor einer Kunstakademie. Als "nouveau regardeur» interessieren ihn die Metamorphosen des Alltäglichen, die Übergänge vom scheinbar festgefügten Alltag in die Paral- lelwelten des Unbewussten. Der Aufenthalt in der Schattenzone, im flirrenden Grenzbereich vom Gewohnten zum Doppelbödigen hat der Stiftung des «Giardino di Daniel Spoerri» das Motto «Hic terminus haeret» vorgegeben. An der Grenze, in unbekannten Bezirken, am Ziel verharren. Terminus, auch ein Beiname des Gottes Jupiter, wacht über das Licht und den Ackerbau und damit über die Übergänge vom Menschwerk zur Natur. Das Vieldeutige des Lateins passt zu einem Meditationsweg, zur Erkundung menschlicher Innenwelten, zu einem existenziellen Erlebnis oder einfach nur zu einer schönen Wanderung durch eine vielseitige Parklandschaft. Spörris Vision beinhaltet alle Varianten, die Besucher und Besucherinnen für sich entdecken können. Wer allen

\section{Daniel Spörri, geboren 1930 in Rumänien,} ist ein Multitalent.

nachleben will, muss sich in der Nähe eine Unterkunft organisieren. Heute zeugen 112 Skulpturen von einer kreativen Initiative, die, neben unzähligen kleineren Parks, die Giardini von Niki de Saint Phalle und Bomarzo in der weiten toskanischen Landschaft zu einem Dreieck ergänzt.

Bildnachweis

Erhard Taverna 